\title{
COATED CLADDING BEHAVIOR DURING HIGH-TEMPERATURE TRANSIENTS
}

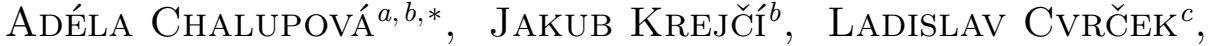 \\ MARTin ŠEVEČEK ${ }^{a}$, VOJTĚCH ROZKOŠNÝ ${ }^{b}$, ANTONÍN PřIBYL $^{b}$, \\ Patricie Halodová ${ }^{d}$, Petra Gávelovád
}

${ }^{a}$ Czech Technical University in Prague, Faculty of Nuclear Sciences and Physical Engineering, Department of Nuclear Reactors, V Holešovičkách 2, 18000 Prague 8, Czech Republic

${ }^{b}$ UJP PRAHA a.s., Nad Kaminkou 1345, 15610 Prague - Zbraslav, Czech Republic

${ }^{c}$ Czech Technical University in Prague, Faculty of Mechanical Engineering, Department of Materials Engineering, Karlovo náměstí 13, 12135 Prague 2, Czech Republic

${ }^{d}$ Research Centre Řež, Hlavni 130, 25068 Husinec- ̌̌ež, Czech Republic

* corresponding author: chaluade@fjfi.cvut.cz

\begin{abstract}
The concept of accident-tolerant fuels has been proposed and widely investigated over the past decade. The contribution is focused on one of the near-term approaches - the modification of the surface of existing Zr-alloy claddings by protective coatings. The studied specimens are based on $\mathrm{Zr}-1 \% \mathrm{Nb}$ substrate with chromium coating, multicomponent chromium nitride and chromium coating and multi-layer chromium nitride/chromium coating deposited by a physical vapor deposition process. Thermomechanical tests were designed to understand the cladding deformation and the burst conditions during the LOCA phenomena. Presented results show both the positive and the negative effect of coating on cladding behavior. All coatings exhibited a reduction of ballooning size and prolongation of time to burst. On the contrary, coating can be connected with larger opening size after burst, higher hydrogen content and deterioration of the local mechanical properties.
\end{abstract}

KEYwords: Nuclear fuel, fuel cladding, LOCA, ATF, coating, PVD.

\section{INTRODUCTION}

One of the main candidates for the near-term Accident Tolerant Fuels (ATF) are coated cladding materials. Surface modifications by specific technologies and various types of coatings have been recently adopted to treat and improve the surface of Zr-based alloys used as cladding materials. The ultimate objective of their development and implementation is to provide longer time before core degradation in case of severe accidents of light water reactors (LWRs) while maintaining or improving the performance during normal operation and transients [1, 2]. Cr-based coatings are currently the most promising from the perspective of both steady-state and accidental performance of LWRs 3 . 5 .

During LOCA transient in WWER reactors, nuclear fuel cladding faces two high-temperature peaks. The first peak can reach temperatures above $1000{ }^{\circ} \mathrm{C}$ for a short time with inner over-pressure ranging between 1 to $2 \mathrm{MPa}$. The temperature during the second peak is about $800{ }^{\circ} \mathrm{C}$ and the cladding is exposed to significantly higher inner over-pressure up to $8 \mathrm{MPa}$. The cladding performance during high-temperature transients defined by both peaks with their characteristic parameters were studied and the results are presented. Coated as well as uncoated reference Zr-based materials are included. The present paper follows the previous articles focused on mechanical and oxidation behavior of coated cladding material $[6-8]$.

\section{Methods}

\subsection{Material AND COATINGS}

All experiments were performed with the reference material $\mathrm{Zr}-1 \% \mathrm{Nb}$, which is used mainly in pressurized water reactors as the fuel cladding material. Nonirradiated segments with the outer diameter of 9.1 $\mathrm{mm}$ and length of $90 \mathrm{~mm}$ were tested. The thickness of the cladding's wall was approximately $0.6 \mathrm{~mm}$. The tests were carried out with reference material as well as with the coated samples.

As the coatings to be tested, chromium, multicomponent chromium nitride and chromium $(\mathrm{CrN}+\mathrm{Cr})$ and multi-layer chromium nitride/chromium coating ( $\mathrm{CrN} / \mathrm{Cr}$ ) were selected. Coatings were deposited by magnetron sputtering from $(99.6 \%) \mathrm{Cr}$ targets in the semi-industrial system Hauzer Flexicoat 850. Before deposition, the samples were ultrasonically cleaned in acetone, ethanol, demineralized water and dried in a furnace. Their surfaces were also cleaned by ion etching in the argon plasma. This process removes the thin Zr-oxide and other impurities in order to improve adhesion of the coating. Coatings were subsequently deposited on outer surfaces in different atmospheres depending on the presence and concentration of nitrogen. Pure chromium coatings were prepared in 


\begin{tabular}{llll}
\hline Coating & $\mathbf{C r}$ & $\mathbf{C r N}+\mathbf{C r}$ & $\mathbf{C r N} / \mathbf{C r}$ \\
\hline Layer 1: Cr $[\mu \mathrm{m}]$ & 15.3 & 11.4 & 10.8 \\
\hline Layer 2: CrN $[\mu \mathrm{m}]$ & - & 5.3 & 1.6 \\
\hline Layer 3: Cr $[\mu \mathrm{m}]$ & - & - & 1.2 \\
\hline Layer 4: CrN $[\mu \mathrm{m}]$ & - & - & 1.2 \\
\hline Layer 5: Cr $[\mu \mathrm{m}]$ & - & - & 1.0 \\
\hline Layer 6: Cr $[\mu \mathrm{m}]$ & - & - & 1.3 \\
\hline Layer 7: Cr $[\mu \mathrm{m}]$ & - & - & 0.6 \\
\hline Total & 15.3 & 16.7 & 17.6 \\
\hline
\end{tabular}

TABLE 1. Measured thicknesses of studied coatings

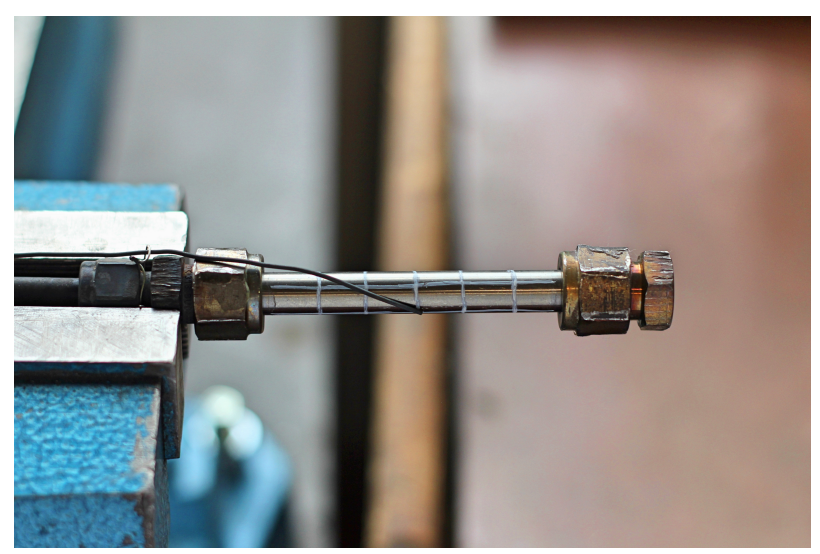

FiguRE 1. Burst-test specimen before exposition in argon

argon atmosphere, whereas $\mathrm{CrN}$ coatings in the gas mixture of argon and nitrogen. The temperature of deposition was around $250{ }^{\circ} \mathrm{C}$. A thin metallic layer was deposited on the substrate first in all cases to improve adhesion of the coating. Thicknesses of the deposited layers are presented in Table 1

\subsection{Burst Test}

Both the reference and the coated specimens were first sealed using end-plugs and then connected to the argon containing reservoir at required gas pressure. Each specimen was equipped with K-thermocouple as shown in Figure 1 .

Afterwards, the specimen was inserted into the preheated resistance furnace with predefined temperature zone $\left( \pm 3{ }^{\circ} \mathrm{C}\right)$ which is about $11 \mathrm{~cm}$ long. The experimental apparatus is shown in Figure 2 Temperature and inner gas pressure propagation were measured. The experiments were done at several temperature levels between 600 and $1100{ }^{\circ} \mathrm{C}$ and with inner pressure from 1 to $10 \mathrm{MPa}$, in an argon environment. The experiments were terminated after cladding failure and consequent pressure decrease.

\subsection{Material Characterization}

Electron backscatter diffraction (EBSD) map was obtained for coatings in the as-received state using

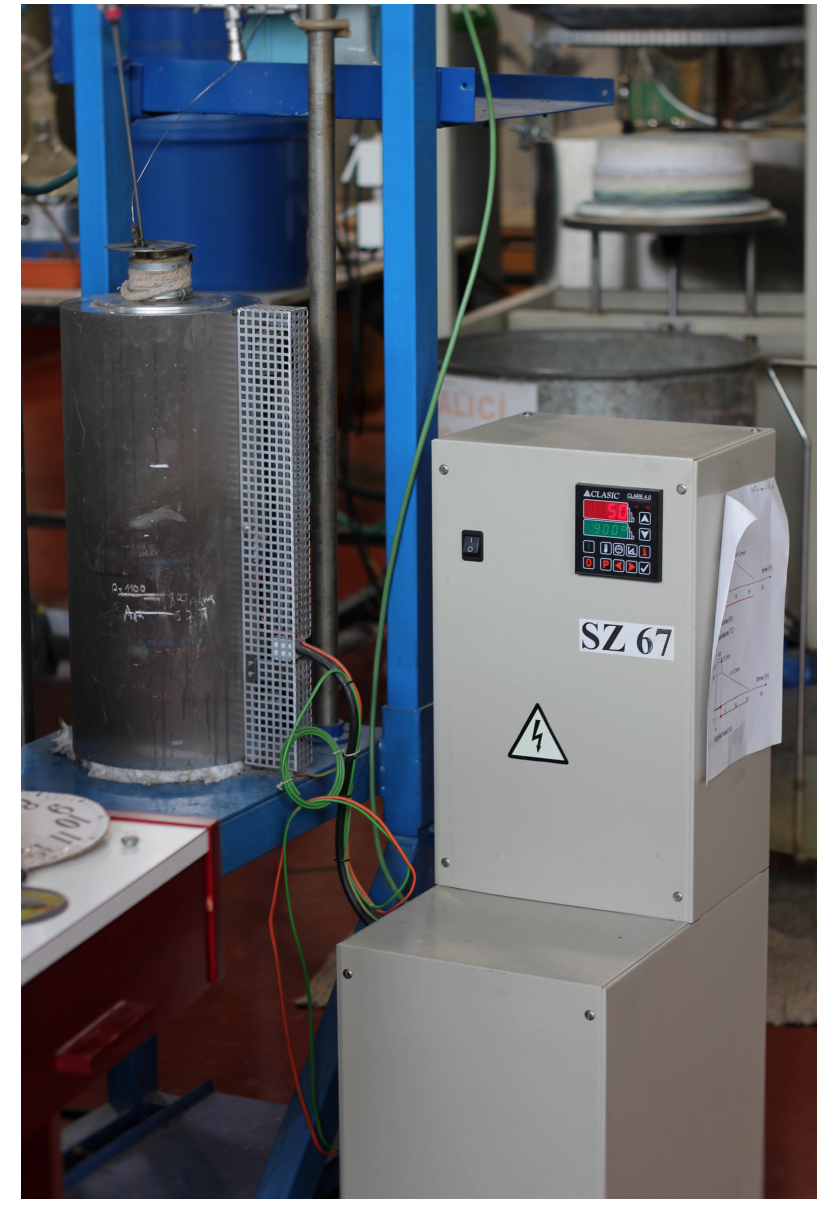

Figure 2. Burst-test experimental apparatus

the Tescan Lyra GMU scanning electron microscope equipped with energy dispersive X-ray spectroscopy (EDS) X-MaxN detector and Nordlys II EBSD detector (Oxford Instruments). The obtained data were post-processed in the "hkl Channel 5" software package.

After burst-test, the cladding diameter was measured in the position of the maximal deformation as well as in the position of $20 \mathrm{~mm}$ from the burstopening (same as in work of Forgeron et al. [9]), where uniform clad deformation occurs. The measurements were carried out both using paper stickers and micrometer. The diameter obtained by measuring with paper stick reflects the creep phenomena while the diameter measured by micrometer has its relevance in potential water flow blockage inside an assembly channel. The deformation in the other cross-sections was evaluated using five diameter measurements with a micrometer. The width and length of the failure was measured using Caliper.

Then, specimens were cut into several rings for further investigation. The metallographic cross sections were prepared using the standard polishing procedure and metallographic evaluation followed. The thickness of the coating, $\mathrm{ZrO}_{2}$ layer and the $\alpha-\mathrm{Zr}(\mathrm{O})$ layer were evaluated. The optical microscope NIKON Elipse MA200 and LUCIA G image analyzer were used for 


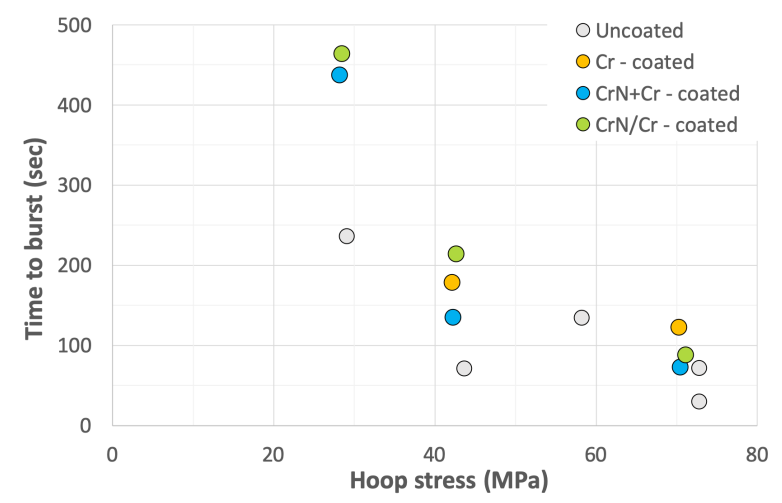

Figure 3. Time to burst at temperature $800{ }^{\circ} \mathrm{C}$ in relation to the hoop stress for different types of coatings and uncoated specimens

the metallographic analysis.

\section{Results}

To analyze data and to compare them with other data obtained, the actual hoop stress $\sigma_{\theta \theta}[\mathrm{MPa}]$ was calculated according to the Equation 1

$$
\sigma_{\theta \theta}=\frac{P(D-t)}{2 t}
$$

where $\mathrm{P}[\mathrm{MPa}]$ is the difference between the internal and the external pressure, $\mathrm{D}$ is the external cladding diameter and $t$ is its thickness.

\subsection{Time to BURST}

First set of tests was simulating the first peak of LOCA transient. The specimens were inserted into the furnace pre-heated at $1100{ }^{\circ} \mathrm{C}$ (heating rate $>25$ ${ }^{\circ} \mathrm{C} /$ sec up to $1000{ }^{\circ} \mathrm{C}$ ). Table 2 shows the results. The second set of experiments focuses on the second LOCA temperature peak. The specimens were inserted into the furnace pre-heated at $800{ }^{\circ} \mathrm{C}$ and were exposed at constant temperature. The main goal was to identify the time to burst. The results of the experiments are summarized in Figure 3 .

All of the coated specimens were more resistant then uncoated specimens. Both, time to burst and burst temperature increased when comparing to the reference samples.

\subsection{Cladding Deformation}

Figure 4 shows the maximal deformation at temperature $1100{ }^{\circ} \mathrm{C}$ in relation to the hoop stress. The comparison of maximal deformation for coated and uncoated specimens at $800{ }^{\circ} \mathrm{C}$ is shown in Figure 5 The size of deformation reduced significantly for all coated specimens. The biggest reduction was for metallic Cr-coated specimens.

Deformation along the length of the specimen has its relevance in water flow blockage in an assembly. Comparison of coated and uncoated specimens deformation after exposure to temperature $800{ }^{\circ} \mathrm{C}$ and inner pressures of $4 \mathrm{MPa}, 6 \mathrm{MPa}$ and $10 \mathrm{MPa}$ are shown

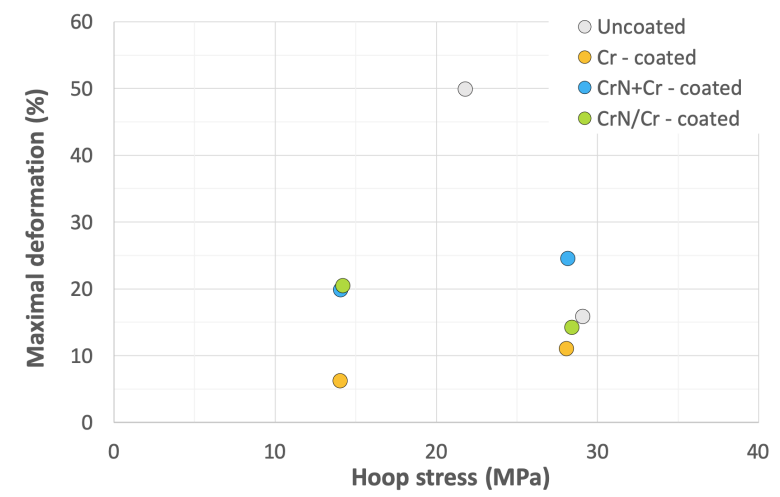

FIgURE 4. Maximal deformation at temperature 1100 ${ }^{\circ} \mathrm{C}$ in relation to hoop stress for different types of coatings and uncoated specimens

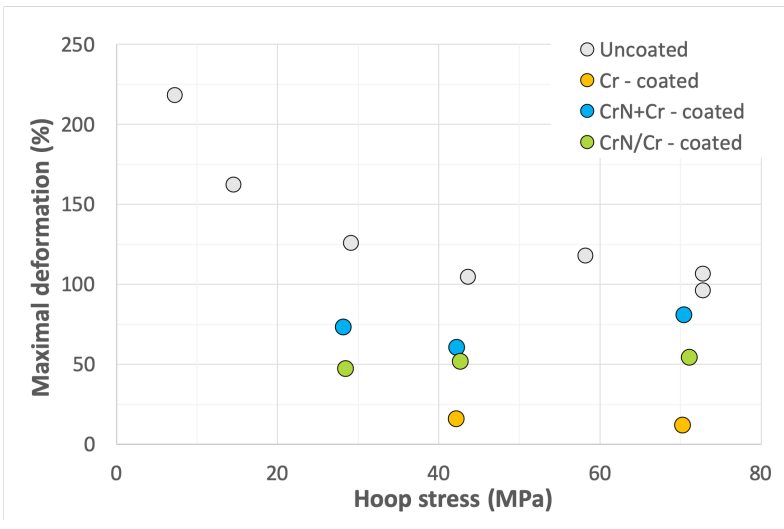

FIgURE 5. Maximal deformation at temperature 800 ${ }^{\circ} \mathrm{C}$ in relation to hoop stress for different types of coatings and uncoated specimens

in Figures 6, 7, 8 The biggest reduction of deformation was for metallic Cr-coated specimens. Multi-layer $\mathrm{CrN} / \mathrm{Cr}$ coating also significantly reduced deformation of the cladding in all cases. Multicomponent $\mathrm{CrN}+\mathrm{Cr}$ coating indicates comparable deformation as the reference uncoated sample.

The size of opening was measured for the coated specimens and reference uncoated specimens as well. The results are summarized in Figure 9 It seems that two mechanisms of cladding failure occur. Crcoated specimens show a low concentration of long cracks with significantly larger openings, whereas on $\mathrm{CrN}+\mathrm{Cr}$ coated specimens is indicated a larger quantity of shorter cracks with smaller openings. This phenomenon is shown in Figure 10

Measured deformation in the position of $20 \mathrm{~mm}$ from the burst-opening, where uniform clad deformation occurs was used to determine creep rate. Results are shown in Figure 11. The rapid discontinuity in creep rate is caused by exposition time and $\alpha-\mathrm{Zr}$ to $\beta$-Zr transformation. When hoop stress exceeds 40 $\mathrm{MPa}$, time to burst is short and the alloy partially stays in $\alpha$-Zr phase with low creep rate. Whereas for hoop stress lower than $40 \mathrm{MPa}$, time to burst is prolonged and alloy forms $\beta$-Zr structure which causes 


\begin{tabular}{llll}
\hline Specimen & Inner pressure $[\mathbf{M P a}]$ & Time to burst $[\mathbf{s}]$ & Burst temperature $\left[{ }^{\circ} \mathbf{C}\right]$ \\
\hline Uncoated & 3 & 13.8 & 1047 \\
\hline Uncoated & 4 & 12.7 & 1061 \\
\hline $\mathrm{Cr}$ & 2 & 34.0 & 1079 \\
\hline $\mathrm{Cr}$ & 4 & 12.7 & 1029 \\
\hline $\mathrm{CrN}+\mathrm{Cr}$ & 2 & 22.6 & 1017 \\
\hline $\mathrm{CrN}+\mathrm{Cr}$ & 4 & 17.9 & 1051 \\
\hline $\mathrm{CrN} / \mathrm{Cr}$ & 2 & 22.6 & 1040 \\
\hline $\mathrm{CrN} / \mathrm{Cr}$ & 4 & 17.9 & 998 \\
\hline
\end{tabular}

TABle 2. Time to burst at temperature $1100{ }^{\circ} \mathrm{C}$ in relation to the hoop stress for different types of coatings and uncoated specimens

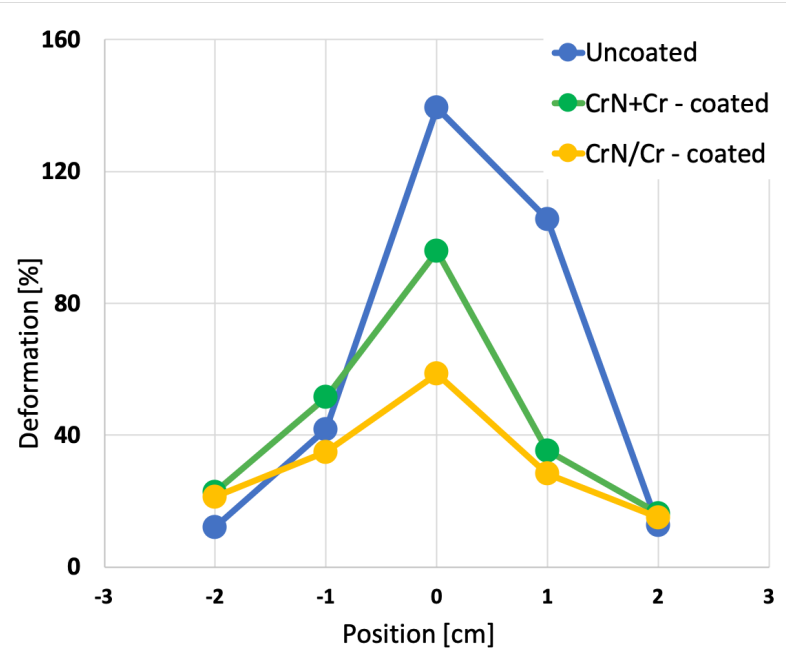

Figure 6. Deformation at temperature $800{ }^{\circ} \mathrm{C}$ under inner pressure of $4 \mathrm{MPa}$ in relation to position for different types of coatings and uncoated specimens

higher creep rate.

\section{Discussion}

As expected, there are many positives related to $\mathrm{Cr}$ coating usage such as reduction of ballooning size and prolongation of time to burst. In the case of using $\mathrm{Cr}$ and $\mathrm{CrN}$ combined layers the ballooning reduction and time to burst are slightly lower compared to metallic chromium but still beneficial. For all coated specimens it was observed that after reaching some level of cladding deformation, the coating cracks and the creep rate locally increases. Therefore, for most of the tested specimens the opening size was bigger for coated than for uncoated specimens. Coated cladding is locally thinned in the cracked area and the stress is localized. Afterward, during the burst it is torn along the whole crack length. Thus it is needed to consider the danger of fuel relocation from a cladding provided that burst openings are larger for coated specimens.

In 2016, a set of isothermal internal pressure creep and preliminary temperature ramp tests were per-

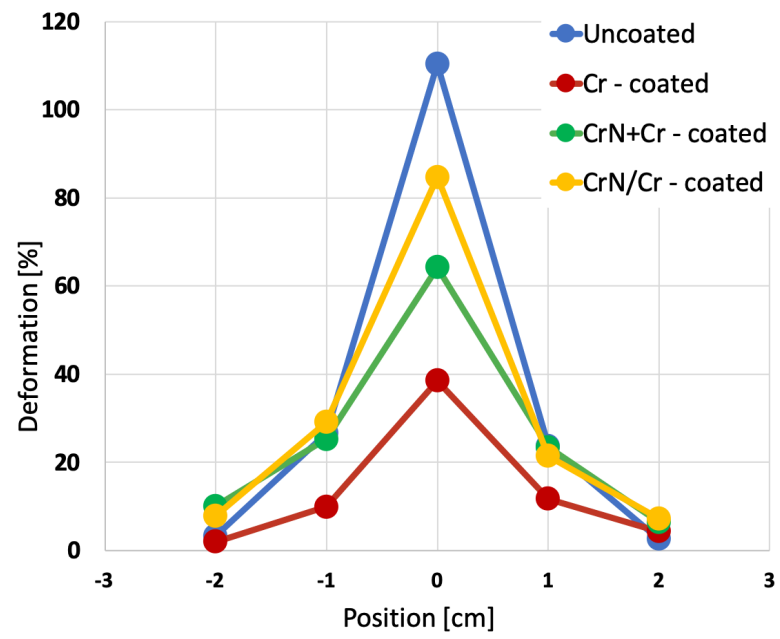

Figure 7. Deformation at temperature $800{ }^{\circ} \mathrm{C}$ under inner pressure of $6 \mathrm{MPa}$ in relation to position for different types of coatings and uncoated specimens

formed at CEA on $\mathrm{Cr}$ coated Zircaloy-4 cladding segments, in a steam environment. [10] It was shown, that the burst resistance of the Cr-coated cladding was improved over the non-coated cladding. The chromium coating was still fully adherent after having experienced ballooning and burst. The results of time to burst and maximal deformation provided by CEA are in good agreement with experiments performed at UJP PRAHA a.s. on chromium coated specimens. However, the author in [10] claims that chromium coating causes smaller burst openings when exposed to temperatures above $800{ }^{\circ} \mathrm{C}$. Experiments presented in this paper show the opposite effect. The burst opening of metallic chromium coated specimens appears to be larger compared to uncoated specimens. In the case of ceramic coatings, burst openings are smaller compared to uncoated specimens. The burst opening may be influenced by $\alpha-\mathrm{Zr}$ to $\beta$-Zr transformation and thus on the heating rate as well as deposition method and thickness of the coating. 


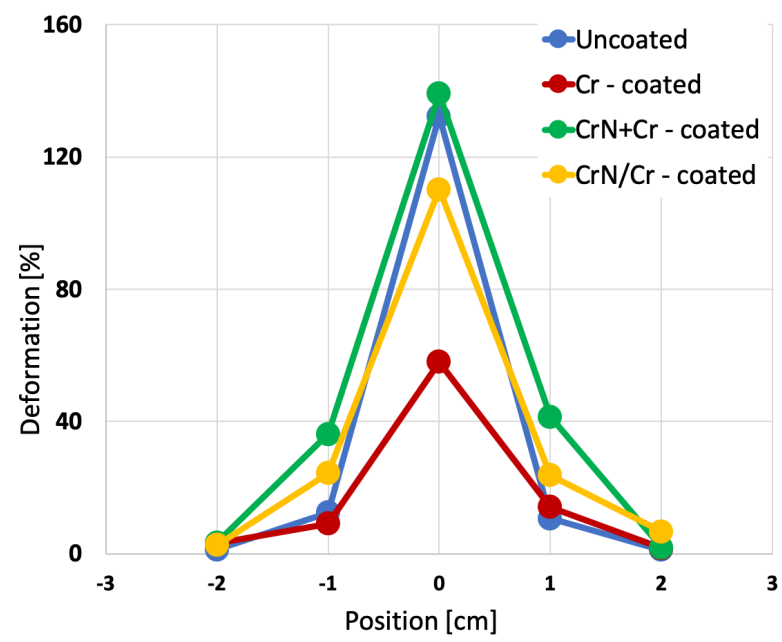

Figure 8. Deformation at temperature $800{ }^{\circ} \mathrm{C}$ under inner pressure of $10 \mathrm{MPa}$ in relation to position for different types of coatings and uncoated specimens

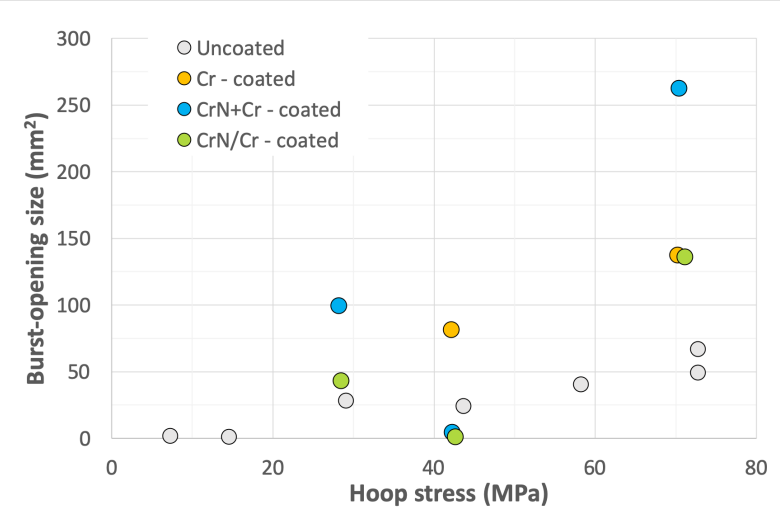

Figure 9. Opening size at temperature $800{ }^{\circ} \mathrm{C}$ in relation to hoop stress for different types of coatings and uncoated specimens

\section{Conclusions}

Presented results show the influence of studied coatings on high-temperature cladding creep and related phenomena such as ballooning size, time to burst and cracking of the coating. There are many benefits related to coating usage such as reduction of the ballooning and prolongation of time to burst. Furthermore, oxidation from the outer side of the coating is reduced and hydrogen release is limited. Nevertheless, some negative effects were identified as well. The coating may be connected with larger opening size, the hydrogen content in the substrate is higher due to oxidation through cracks and the local mechanical properties can be deteriorated due to $\mathrm{Cr}$ diffusion into the substrate in the cracked areas. It is also necessary to mention that burst-tests examine only a part of cladding material performance and for further description of coated cladding behavior more complex LOCA experiments are needed.
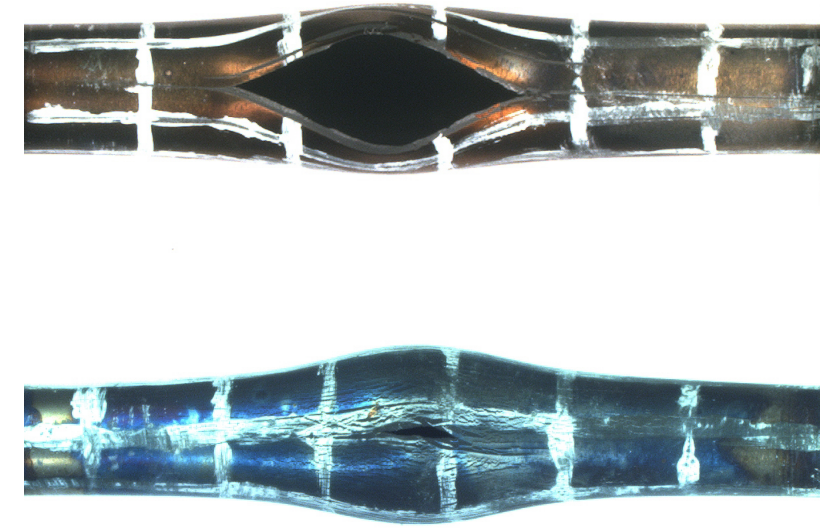

Figure 10. Coated specimen with Cr (above) and $\mathrm{CrN}+\mathrm{Cr}$ (below) after exposure to $800{ }^{\circ} \mathrm{C}$ and inner pressure $6 \mathrm{MPa}$

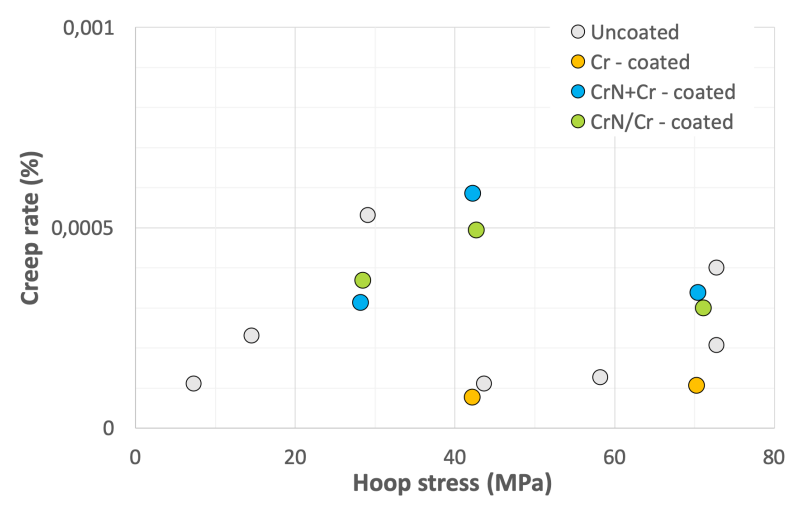

Figure 11. Creep rate at temperature $800{ }^{\circ} \mathrm{C}$ in relation to hoop stress for different types of coatings and uncoated specimens

\section{ACKNOWLEDGEMENTS}

The authors thank the whole UJP-zirconium department (namely: J. Šustr, J. Kabátová, D. Rada, F. Manoch, A. Přibyl, and V. Vrtílková) for sample preparation, and post-experimental evaluation. Financial support of this research through ČEZ a.s. company is gratefully acknowledged. Also, this work was supported by the Ministry of Education, Youth and Sport of the Czech Republic, programme NPU1, project No LO1207, National Programme of Sustainability II Project LQ1603 (Research for SUSEN), and IAEA CRP 21065, Technology Agency of the Czech Republic grant No. TH02020477, TH02020691, CZ.2.16/3.1.00/21563.

\section{REFERENCES}

[1] S. J. Zinkle, K. A. Terrani, J. C. Gehin, et al. Accident tolerant fuels for lwrs: A perspective. $J$ Nucl Mater 488(1-3):374-379, 2014.

[2] N. OECD. State-of-the-art report on light water reactor accident-tolerant fuels $\mathbf{2 0 1 8}$.

[3] D. J. Park, H.-G. Kim, Y. Il Jung, et al. Behavior of an improved zr fuel cladding with oxidation resistant 
coating under loss-of-coolant accident conditions. Journal of Nuclear Materials 482, 2016. DOI:10.1016/j.jnucmat.2016.10.021

[4] C. Tang, M. S. . H. J. Seifert, M. Steinbrück. Protective coatings on zirconium-based alloys as accident-Tolerant fuel (ATF) claddings. Corrosion Reviews (35), 2017.

[5] J.-C. Brachet, C. Lorrette, A. Michaux, et al. CEA studies on advanced nuclear fuel claddings for enhanced Accident Tolerant LWRs Fuel (LOCA and beyond LOCA conditions). 2014. DOI:10.13140/2.1.5105.6325.

[6] J. Krejčí, M. Ševeček, L. Cvrček, et al. Chromium and Chromium Nitride Coated Cladding for Nuclear Reactor Fuel. EUROCORR 2017.

[7] J. Krejčí, M. Ševeček, J. Kabátová, et al. Experimental Behavior Of Chromium-based Coatings. 2018.
[8] J. Krejčí, M. Ševeček, L. Cvrček. Development of chromium and chromium nitride coated cladding for VVER reactors. WRFPM 2017.

[9] T. Forgeron, J.-C. Brachet, F. Barcelo, et al. Experiment and modeling of advanced fuel rod cladding behavior under LOCA conditions: Alpha-beta phase transformation kinetics and EDGAR methodology. ASTM Special Technical Publication pp. 256-278, 2000. DOI:10.1520/STP14303S

[10] J. Brachet, M. L. Saux, M. Dumerval, et al. Behavior under LOCA conditions of Enhanced Accident Tolerant Chromium Coated Zircaloy-4 Claddings 6:2-3, 2016. 